\title{
DFT study of stabilization effects on N-doped graphene for ORR catalysis
}

\author{
Reda, Mateusz; Hansen, Heine Anton; Vegge, Tejs
}

Published in:

Catalysis Today

Link to article, DOI:

10.1016/j.cattod.2018.02.015

Publication date:

2018

Document Version

Peer reviewed version

Link back to DTU Orbit

\section{Citation (APA):}

Reda, M., Hansen, H. A., \& Vegge, T. (2018). DFT study of stabilization effects on N-doped graphene for ORR catalysis. Catalysis Today, 312, 118-125. https://doi.org/10.1016/j.cattod.2018.02.015

\section{General rights}

Copyright and moral rights for the publications made accessible in the public portal are retained by the authors and/or other copyright owners and it is a condition of accessing publications that users recognise and abide by the legal requirements associated with these rights.

- Users may download and print one copy of any publication from the public portal for the purpose of private study or research.

- You may not further distribute the material or use it for any profit-making activity or commercial gain

- You may freely distribute the URL identifying the publication in the public portal 


\section{Accepted Manuscript}

Title: DFT Study of Stabilization Effects on N-doped Graphene for ORR Catalysis

Author: Mateusz Reda Heine Anton Hansen Tejs Vegge

PII: $\quad$ S0920-5861(18)30066-X

DOI: $\quad$ https://doi.org/doi:10.1016/j.cattod.2018.02.015

Reference: $\quad$ CATTOD 11240

To appear in: $\quad$ Catalysis Today

Received date: $\quad 18-12-2017$

Revised date: $\quad$ 2-2-2018

Accepted date: $\quad$ 9-2-2018

Please cite this article as: Mateusz Reda, Heine Anton Hansen, Tejs Vegge, DFT Study of Stabilization Effects on N-doped Graphene for ORR Catalysis, <! [CDATA[Catalysis Today]]> (2018), https://doi.org/10.1016/j.cattod.2018.02.015

This is a PDF file of an unedited manuscript that has been accepted for publication. As a service to our customers we are providing this early version of the manuscript. The manuscript will undergo copyediting, typesetting, and review of the resulting proof before it is published in its final form. Please note that during the production process errors may be discovered which could affect the content, and all legal disclaimers that apply to the journal pertain. 


\title{
DFT Study of Stabilization Effects on N-doped Graphene for ORR Catalysis
}

\author{
Mateusz Reda ${ }^{\mathrm{a}}$, Heine Anton Hansen ${ }^{\mathrm{a}, *}$, Tejs Vegge ${ }^{\mathrm{a}}$ \\ ${ }^{a}$ Department of Energy Conversion and Storage, Technical University of Denmark, \\ DK-2800 Kgs. Lyngby, Denmark
}

\begin{abstract}
Noble metal free catalysts, such as N-doped graphene, have drawn a lot of attention as a promising replacement for platinum in low temperature fuel cells. Computational prediction of catalytic activity requires accurate description of the oxygen reduction reaction (ORR) intermediates adsorption energies. Two stabilizing effects, immanently present in experimental ORR setups with basal plane N-doped graphene catalyst, are studied systematically by means of the Density Functional Theory. Free nitrogen selectively stabilizes *O and $* \mathrm{O}_{2}$ adsorbates. Water solvation stabilizes all ORR intermediates, having a greater impact on ${ }^{*} \mathrm{O}$ and $* \mathrm{O}_{2}$, than on $* \mathrm{OH}$ and $* \mathrm{OOH}$, in contrast to metal and oxide catalysts. Synergistic stabilization of *O caused by both effects reaches remarkably high value of $1.5 \mathrm{eV}$ for nitrogen concentrations above 4.2 at $\%$ N. Such a strong effect is explained by a high reactivity of $* \mathrm{O}$ and $* \mathrm{O}_{2}$, which possess empty $\mathrm{O}(\mathrm{sp})$ states. At $6.25 \% \mathrm{~N}$, the reaction environment is found to comprise of $* \mathrm{O}$ and free nitrogen spectators. Strong ${ }^{*} \mathrm{O}$ solvation is found to be present in a broader class of systems, comprising all materials where the ORR occurs on a $2^{\text {nd }}$ row element. Including at least a
\end{abstract}

\footnotetext{
*Corresponding author, heih@dtu.dk
} 
single explicit water layer is inevitable for the correct description of the ORR intermediates adsorption energies on these materials.

Keywords: Oxygen reduction reaction, Density Functional Theory, N-doped graphene, Explicit solvation

\section{Introduction}

Low temperature fuel cells have been recognized as one of the most attractive alternatives to combustion engines for automotive applications [1]. The promise of higher energy efficiency, independence from limited resources of fossil fuels and reduction in air pollution drives the research to overcome the obstacles to commercialization of this technology. Some of the difficulties are related to the development of auxiliary technologies, such as hydrogen production via water splitting and effective hydrogen storage [2], but the most troublesome issue directly related to the fuel cell stack is finding a durable material, which would efficiently catalyze the sluggish oxygen reduction reaction (ORR) [3].

Most commonly utilized cathodic materials for fuel cells are currently based on platinum $[4,3]$. However, due to its price and scarcity, methods of decreasing Pt loading, or completely replacing it with earth-abundant alternatives, are intensively explored $[5,6,3,7,8,9]$. The latter possibility is particularly attractive, as it may allow to further reduce the cost of the technology.

Setting aside arguably the most promising non-precious ORR catalysts containing a $\mathrm{FeN}_{4}$ moiety $[10,11]$, we draw attention to metal-free materials. This class of ORR catalysts is dominated by conductive carbon nanostruc- 
tures, modified by various types of doping, especially nitrogen doping [7, 9]. In recent years, N-doped carbon nanotubes and graphene have been extensively studied both experimentally and computationally. Theoretical approaches investigated, among other things, effects such as: type of nitrogen doping (graphitic, pyridinic, pyrrolic) [12], morphology and concentration of N-dopants [13], structural defects [14, 15], curvature effect [14], solvation of * $\mathrm{O}_{2}$ [16] and other ORR intermediates [17] by water, and the influence of additional nitrogen dopants on $* \mathrm{O}_{2}[16]$ and $* \mathrm{O}[18]$ stability $(*=$ active site on the catalyst's surface).

In the present paper, the latter two effects are revisited and reassessed. Unoccupied nitrogen dopant in the cell, referred to as "free nitrogen", is a nitrogen atom, where neighboring carbon atoms remain being empty adsorption sites. Such nitrogen is particularly interesting due to its selective stabilization of $* \mathrm{O}$ over $* \mathrm{OH}$ and $* \mathrm{OOH}[18]$. Similarly, the presence of water was found to stabilize ${ }^{*} \mathrm{O}_{2}$ adsorbate by a uniquely high value of $0.83 \mathrm{eV}$, twice as much as ${ }^{*} \mathrm{OH}[17]$. In what follows, the influence of these two effects on all ORR intermediates is systematically studied as a function of nitrogen concentrations, number of nitrogen atoms per adsorbate and number of water molecules per adsorbate. We employ Bader charge analysis [19] and projected density of states (PDOS) calculations to gain insight into the underlaying phenomena and explain why different ORR intermediates respond differently to both effects. Finally, we include a case study of the oxygen reduction process on a selected catalytic system to show how our findings are applicable to the ORR modeling. 


\section{Computational methods}

All Density Functional Theory (DFT) calculations are done using Atomic Simulation Environment (ASE) [20] coupled with the Vienna Ab Initio Simulation Package (VASP) [21, 22, 23, 24]. The core electrons are described with the projector augmented wave method [25, 26], and the basis set for the electronic wavefunctions are plane waves below a $400 \mathrm{eV}$ energy cutoff. We use a Fermi smearing of electronic occupations with a width of $0.1 \mathrm{eV}$ and Monkhorst-Pack [27] mesh for the Brillouin zone sampling of $\left(k_{1}, k_{2}, 1\right)$, with $k_{i}$ such that $k_{i} v_{i}>40$ for $v_{i}$ being the corresponding lattice vector. The structure relaxation is performed until the maximum force on each atom drops below $0.01 \mathrm{eV} / \AA$.

In this study, we consider systems in which water molecules interact with one another and with hydrophobic surface of the catalyst. In such systems, dispersion forces can play a significant role, and semilocal exchangecorrelation functionals like PBE [28] or RPBE [29] do not account for nonlocal van der Waals interactions. Here, we employ BEEF-vdW [30] functional in which vdW-DF2 [31] non-local correlation is used. This approach proved to be successful in predicting adsorption bond energies both to transition metal surfaces [32] and carbon-based materials [30], as well as adsorption energy error estimation [33].

Solvation of the surface and adsorbates is taken into account by including water implicitly or explicitly. For implicit solvent calculations we use the continuum solvation model implemented in VASPsol $[34,35]$ with a 600 $\mathrm{eV}$ plane wave cutoff. Explicit water layer structures are determined by the minima hopping algorithm implemented in ASE [36, 37]. This global 
optimization method was accompanied by additional sampling of minimas, achieved by manual change of orientations of those $\mathrm{H}_{2} \mathrm{O}$ molecules, which hydrogen atoms can point either towards or away from the surface. The vacuum layer region between periodic images of the system is about $10 \AA$. Dipole correction is used to decouple electrostatic potentials on the two sides of the two-dimensional structure.

The free energy corrections for adsorbed species are based on the quantum mechanical harmonic approximation and calculated vibrational frequencies. For calculations of the free energy diagrams, the total energy of the gas phase $\mathrm{O}_{2}$ is corrected based on the formation Gibbs free energy of liquid $\mathrm{H}_{2} \mathrm{O}$ as described previously [38], and the total energies of the systems with adsorbates are corrected according to the Christensen's correction scheme $[39,40]: \Delta E(\mathrm{O}-\mathrm{O})=0.2 \mathrm{eV}, \Delta E\left(\mathrm{H}_{2} \mathrm{O}\right)=-0.03 \mathrm{eV}$, and $\Delta E\left(\mathrm{H}_{2}\right)=0.09$ $\mathrm{eV}$.

\section{Results}

All considered N-doped graphene models consist of graphitic nitrogen atoms uniformly dispersed in the graphene sheet. When a nitrogen atom is introduced into the system preserving its unit cell, it is placed in a position that maximizes the distance between nitrogen atoms. In that case, uniformity of $\mathrm{N}$ distribution cannot be strictly preserved. However, all the studied properties of the system are found to be insensitive to such deviations from uniformity. Non-uniform dopant distribution, such as nitrogen clustering, introduces another degree of freedom and is beyond the scope of this study.

The studied NG model systems are referred to in the following format: 


$$
\mathrm{NG} \_x_{-} y \mathrm{~N} / \mathrm{ads} / z \mathrm{H}_{2} \mathrm{O}
$$

where: $x$ - nitrogen concentration (atomic ratio), $y-\mathrm{N} / *$ ads ratio, ads - considered adsorbate $\left(\mathrm{O}, \mathrm{OH}, \mathrm{OOH}\right.$ or $\mathrm{O}_{2}$ for a specific adsorbate, or "ads" for general considerations), $z-\mathrm{H}_{2} \mathrm{O} /{ }^{*}$ ads ratio. For example, $\mathrm{NG}_{-} 4.2 \% \_2 \mathrm{~N} / \mathrm{O} / 11 \mathrm{H}_{2} \mathrm{O}$ denotes nitrogen-doped graphene with $4.2 \%$ of nitrogen, atomic oxygen adsorbate, $\mathrm{N} / * \mathrm{O}$ ratio of 2 and $\mathrm{H}_{2} \mathrm{O} /{ }^{*} \mathrm{O}$ ratio of 11 .

Adsorption energies are defined as the DFT energies of the following reactions:

$$
\begin{array}{lc}
*+\mathrm{H}_{2} \mathrm{O} \rightarrow * \mathrm{O}+\mathrm{H}_{2}, & \Delta_{\text {ads }} E(\mathrm{O}) \\
*+\mathrm{H}_{2} \mathrm{O} \rightarrow * \mathrm{OH}+\frac{1}{2} \mathrm{H}_{2}, & \Delta_{\text {ads }} E(\mathrm{OH}) \\
*+2 \mathrm{H}_{2} \mathrm{O} \rightarrow * \mathrm{OOH}+\frac{3}{2} \mathrm{H}_{2}, & \Delta_{\text {ads }} E(\mathrm{OOH}) \\
*+\mathrm{O}_{2} \rightarrow * \mathrm{O}_{2}, & \Delta_{\text {ads }} E\left(\mathrm{O}_{2}\right)
\end{array}
$$

Superscripts are added when considering adsorption energies in the presence of free nitrogen $\left[\Delta_{\text {ads }}^{\mathrm{N}} E(\mathrm{O})\right]$, water $\left[\Delta_{\mathrm{ads}}^{\mathrm{W}} E(\mathrm{O})\right]$ or both $\left[\Delta_{\mathrm{ads}}^{\mathrm{N}+\mathrm{W}} E(\mathrm{O})\right]$.

Stabilization by free nitrogen is the difference between the adsorption energy in $1 \mathrm{~N} /{ }^{*}$ ads system (no free nitrogen, e.g. Fig. 1a or $1 \mathrm{~d}$ ) and $>1 \mathrm{~N} /{ }^{*}$ ads systems:

$$
\Delta_{\mathrm{stab}}^{\mathrm{N}} E(\mathrm{X})=\Delta_{\mathrm{ads}} E(\mathrm{X})-\Delta_{\mathrm{ads}}^{\mathrm{N}} E(\mathrm{X})
$$

The energy of stabilization via solvation is the difference between ORR adsorption energies in vacuum and in water, and equals the negative solvation energy:

$$
\Delta_{\mathrm{stab}}^{\mathrm{W}} E(\mathrm{X})=-\Delta_{\mathrm{solv}} E(\mathrm{X})=\Delta_{\mathrm{ads}} E(\mathrm{X})-\Delta_{\mathrm{ads}}^{\mathrm{W}} E(\mathrm{X})
$$


To calculate the adsorption energy in the presence of water, one $\mathrm{H}_{2} \mathrm{O}$ molecule from the water layer is replaced with adsorbate. The energy of that water molecule is assumed to be the average energy of $\mathrm{H}_{2} \mathrm{O}$ in the water layer.

\subsection{Stabilization by free nitrogen}

It is well known that a nitrogen dopant embedded in a graphene structure creates net positive charge on adjacent carbon atoms, making them more favorable for $\mathrm{O}_{2}$ adsorption and facilitating the oxygen reduction reaction [41]. More recently, it was found that free nitrogen atoms which are located far away from the active site stabilize certain ORR adsorbates as well [18].

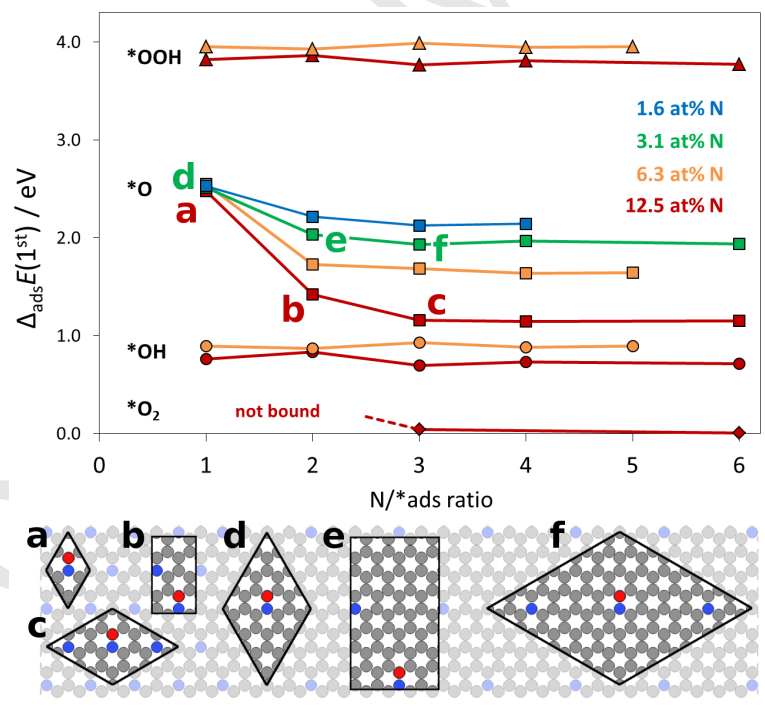

Figure 1: First adsorption energy, $\Delta_{\text {ads }} E\left(1^{\text {st }}\right)$, vs. $\mathrm{N} / *^{*}$ ads ratio at different nitrogen concentrations; ads $=\left\{\mathrm{O}, \mathrm{OH}, \mathrm{OOH}, \mathrm{O}_{2}\right\}$. Sample unit cell structures are marked on the figure with letters (a)-(f). Color code for atoms: gray - carbon, blue - nitrogen, red oxygen. 
The effect of up to five free nitrogen atoms on the adsorption energy of ORR intermediates at different $\mathrm{N}$ concentrations is shown in Fig. 1. The $\mathrm{OH}$ and $\mathrm{OOH}$ adsorption energies are essentially independent of the $\mathrm{N} /{ }^{*}$ ads ratio, only fluctuations of $\pm 0.05 \mathrm{eV}$ are observed. By contrast, atomic oxygen is significantly stabilized by additional unoccupied nitrogen present in the cell. This effect is most apparent when the first free nitrogen appears in the cell: oxygen binding energy increases by up to $1.05 \mathrm{eV}($ for $12.5 \% \mathrm{~N})$. Introduction of the second free nitrogen further stabilizes oxygen, especially at high nitrogen concentrations $\left(0.26 \mathrm{eV}\right.$ stabilization of $3 \mathrm{~N} /{ }^{*} \mathrm{O}$ relative to $2 \mathrm{~N} / * \mathrm{O}$ at $12.5 \% \mathrm{~N})$. A higher $\mathrm{N} /{ }^{*} \mathrm{O}$ ratio than 3 has marginal effect on the stability of $*$ O.

Stabilization by free $\mathrm{N}$ vanishes with decreasing nitrogen concentration. For systems with uniform $\mathrm{N}$ distribution this is understandable. In these systems, nitrogen concentration is strictly related to $\mathrm{N}-\mathrm{N}$ distance $\left(d_{\mathrm{N}-\mathrm{N}}\right)$, so in the limit of $d_{\mathrm{N}-\mathrm{N}} \rightarrow \infty$ (equivalent to $0 \% \mathrm{~N}$ ), the local environment around adsorption site is the same, irrespective of the $\mathrm{N} / *^{*} \mathrm{O}$ ratio. Nonetheless, the influence of free nitrogen on oxygen binding proves to be a long-range effect. For instance, the stabilization of oxygen by two free nitrogen atoms at $1.6 \% \mathrm{~N}$ is around $0.4 \mathrm{eV}$, while the $\mathrm{N}-\mathrm{N}$ distance is $14.8 \AA$. Moreover, we observe a hyperbolic decay of $\Delta_{\mathrm{stab}}^{\mathrm{N}} E(\mathrm{O})$ with $\mathrm{N}-\mathrm{N}$ distance (Fig. S1, Supporting Information), which brings to mind electrostatic (Coulomb) potential between point charges. Proposed explanation of this phenomenon is presented in the discussion section.

The effect of stabilization by free nitrogen becomes even more significant for molecular oxygen, as the presence of at least 2 free nitrogen atoms $\left(\mathrm{N} /{ }^{*} \mathrm{O}_{2}\right.$ 
$\geqslant 3)$ appears to be a prerequisite for $\mathrm{O}_{2}$ chemisorption at $12.5 \% \mathrm{~N}$. We also note that for considered nitrogen concentrations, $12.5 \% \mathrm{~N}$ was the only one that assured $\mathrm{O}_{2}$ chemisorption, whereas lower concentrations did not. ${ }^{*} \mathrm{O}_{2}$ is similar to ${ }^{*} \mathrm{O}$ in that its binding energy strongly depends on the presence of free nitrogen atoms in the cell.

\subsection{Stabilization via solvation}

ORR intermediates adsorption energies depend on many parameters characterizing the environment near fuel cell cathode, such as the presence of water [42], pH of the electrolyte [43] or applied field [44]. Here we focus on the solvation effect caused by explicit water molecules.

The water effect is well-studied with $\mathrm{Pt}(111)$ as catalyst $[42,45,46]$, and is often assumed to be transferable to other classes of materials $[18,47]$. There is some evidence, however, that $\Delta_{\text {stab }}^{\mathrm{W}} E(\mathrm{X})$ can vary a lot between different catalyst materials. For instance, water has negligible effect on the stability of atomic oxygen found in fcc hollow sites on Pt(111) surface [42], but the same oxygen adsorbed on top of carbon atom in basal plane N-doped graphene is stabilized in aqueous environment by about $0.5 \mathrm{eV}$ [17].

Here, we first study how a single water layer influences ORR intermediates adsorption at different water-to-adsorbate ratios $\left(\mathrm{H}_{2} \mathrm{O} /{ }^{*}\right.$ ads $)$. The surface density of water in our model is $0.25 \mathrm{H}_{2} \mathrm{O}$ molecules per each atom in the N-graphene sheet, which corresponds to about $5 \%$ average expansive strain on the water layer relative to hexagonal ice. This model allows to study water effect across many different $\mathrm{N}$ concentrations and $\mathrm{H}_{2} \mathrm{O} /{ }^{*}$ ads ratios. Hexagonal water arrangements were found to be the most stable by the minima-hopping algorithm both for clean and adsorbate-covered N-graphene 
surfaces (sample structures are shown in Fig. S2, Supporting Information). Unlike the case of the $\mathrm{Pt}(111)$ surface [48] and catalysts containing $\mathrm{FeN}_{4}$ moieties [49], water molecules do not chemisorb on the active site of N-doped graphene. The average separation between the N-graphene sheet and water oxygen atoms is $c a$. $3.7 \AA$. The energy of a single water layer adhesion to graphene and $\mathrm{N}$-graphene $(6.25 \% \mathrm{~N})$ is 79 and $82 \mathrm{meV}$ per water molecule, respectively.

For both $* \mathrm{OH}$ and $* \mathrm{OOH}$ intermediates, the solvation-based stabilization energy is $\Delta_{\text {stab }}^{\mathrm{W}} E(\mathrm{X})=0.19 \pm 0.02 \mathrm{eV}$, irrespective of nitrogen concentration, $\mathrm{H}_{2} \mathrm{O} /{ }^{*}$ ads ratio or $\mathrm{N} /{ }^{*}$ ads ratio. The situation is different for $* \mathrm{O}$, where $\Delta_{\text {stab }}^{\mathrm{W}} E(\mathrm{O})$ depends on the $\mathrm{H}_{2} \mathrm{O} /{ }^{*} \mathrm{O}$ ratio. For systems without free nitrogen, stabilization energy can be viewed as a difference between $1 \mathrm{~N} /{ }^{*} \mathrm{O}$ and $1 \mathrm{~N} /{ }^{*} \mathrm{O}+\mathrm{H}_{2} \mathrm{O}$ curves in Fig. 2. At low water-to-adsorbate ratios $\left(\mathrm{H}_{2} \mathrm{O} /{ }^{*} \mathrm{O}=5\right)$, the stabilization energy is $0.38 \mathrm{eV}$, and increases with increasing $\mathrm{H}_{2} \mathrm{O} /{ }^{*} \mathrm{O}$ until reaching a plateau (ca. $0.65 \mathrm{eV}$ ) at $11 \mathrm{H}_{2} \mathrm{O} /{ }^{*} \mathrm{O}$. Increasing $\mathrm{H}_{2} \mathrm{O} /{ }^{*} \mathrm{O}$ further has practically no effect on the stabilization en$\operatorname{ergy}\left(\right.$ e.g. $\Delta_{\text {stab }}^{\mathrm{W}} E(\mathrm{O})=0.67 \mathrm{eV}$ at $\left.31 \mathrm{H}_{2} \mathrm{O} /{ }^{*} \mathrm{O}\right)$. The plateau suggests that 2-3 coordination shells of water participate in the stabilization of *O. A similar analysis for systems with free nitrogen (difference between $2 \mathrm{~N} /{ }^{*} \mathrm{O}$ and $2 \mathrm{~N} / * \mathrm{O}+\mathrm{H}_{2} \mathrm{O}$ curves in Fig. 2) leads to the same conclusion, though in this case stabilization energies are about $0.17 \mathrm{eV}$ higher.

A similar trend is found for the ${ }^{*} \mathrm{O}_{2}$ adsorbate. The stabilization energy is 0.67 and 1.05 eV for $\mathrm{NG}_{-} 12.5 \% \_3 \mathrm{~N} / \mathrm{O}_{2} / 5 \mathrm{H}_{2} \mathrm{O}$ and $\mathrm{NG}_{-} 12.5 \% \_6 \mathrm{~N} / \mathrm{O}_{2} / 11 \mathrm{H}_{2} \mathrm{O}$ systems, respectively. 
$0.5 d_{\mathrm{N}-\mathrm{N}} / \AA ̊ A\left(1 \mathrm{~N} /{ }^{*} \mathrm{O}\right.$ systems: red, orange) or $d_{\mathrm{N}-\mathrm{N}} / \AA \AA$ ( $2 \mathrm{~N} /{ }^{*} \mathrm{O}$ systems: blue, gray, green)

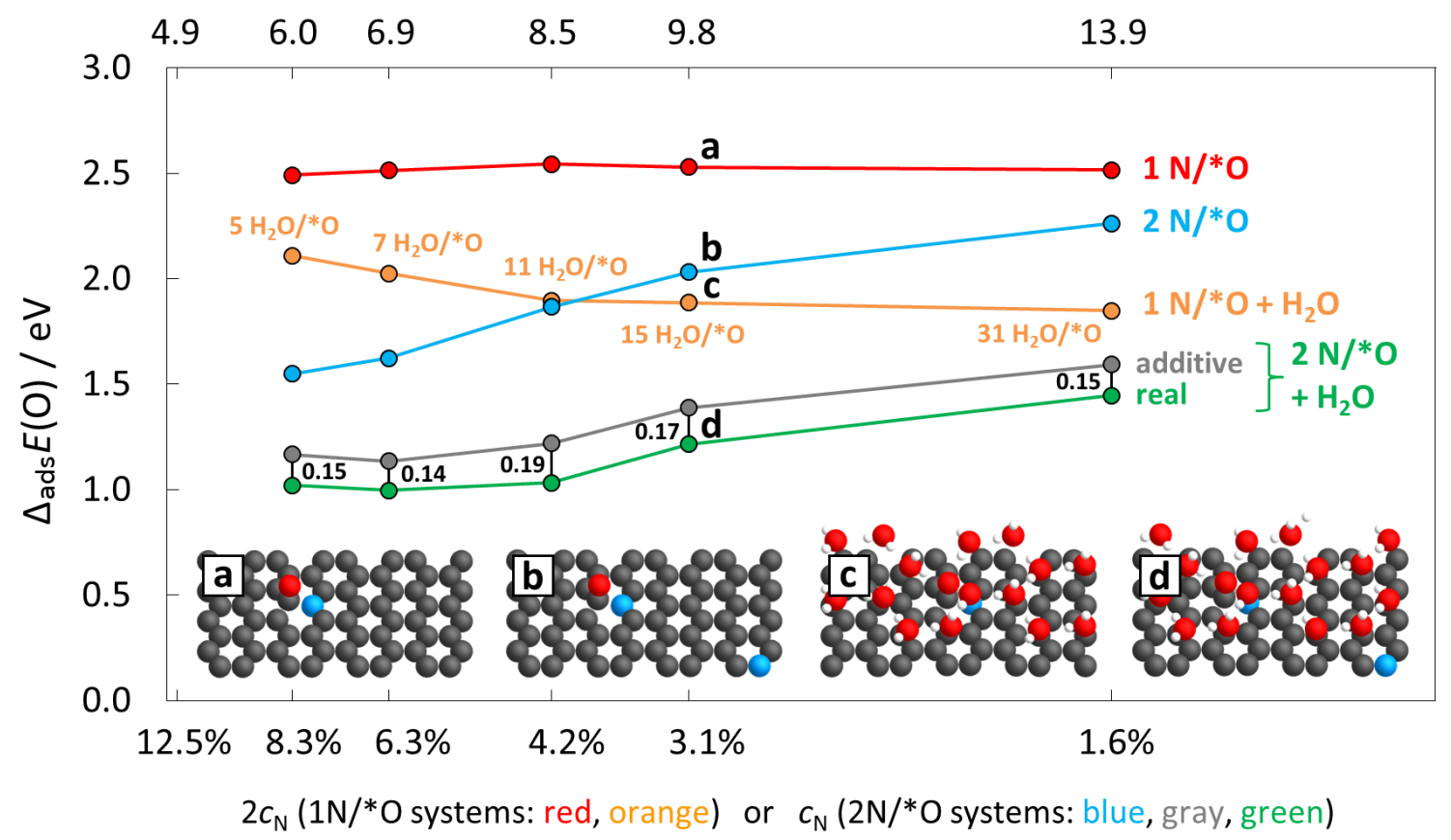

Figure 2: Atomic oxygen adsorption energy on N-doped graphene as a function of N-N distance (or $\mathrm{N}$ concentration) in the following scenarios: (i) in vacuum, $1 \mathrm{~N} /{ }^{*} \mathrm{O}$ (red), (ii) in vacuum, $2 \mathrm{~N} /{ }^{*} \mathrm{O}$ (blue), (iii) in water, $1 \mathrm{~N} /{ }^{*} \mathrm{O}$ (orange), (iv) in water, $2 \mathrm{~N} /{ }^{*} \mathrm{O}$ (green), (v) in water, $2 \mathrm{~N} /{ }^{*} \mathrm{O}$, assuming additivity of the free $\mathrm{N}$ and $\mathrm{H}_{2} \mathrm{O}$ stabilizing effects (gray). Sample structures for systems containing 64 atoms in N-graphene unit cell are shown as inset. Color code for atoms: dark gray - carbon, blue - nitrogen, red - oxygen, white hydrogen.

\subsection{Synergy of the two effects}

As mentioned previously, the solvation effect becomes stronger in the presence of free nitrogen. Equivalently, free nitrogen effect becomes stronger in the presence of water, i.e. the two effects synergistically stabilize ${ }^{*} \mathrm{O}$. This 
can be expressed as

$$
\Delta_{\mathrm{stab}}^{\mathrm{N}+\mathrm{W}} E(\mathrm{O})=\Delta_{\mathrm{stab}}^{\mathrm{N}} E(\mathrm{O})+\Delta_{\mathrm{stab}}^{\mathrm{W}} E(\mathrm{O})+\Delta_{\mathrm{stab}}^{\mathrm{syn}} E(\mathrm{O})
$$

where the synergy component is $\Delta_{\text {stab }}^{\text {syn }} E(\mathrm{O})=0.17 \pm 0.02 \mathrm{eV}$ (Fig. 2).

For high nitrogen concentration, the total stabilizing effect reaches a remarkably high value of $1.5 \mathrm{eV}$, and is approximately constant down to $4.2 \% \mathrm{~N}$, due to the opposite changes of $\Delta_{\mathrm{stab}}^{\mathrm{N}} E(\mathrm{O})$ and $\Delta_{\mathrm{stab}}^{\mathrm{W}} E(\mathrm{O})$ with nitrogen concentration. Below $4.2 \% \mathrm{~N}$, solvation effect reaches its maximum and stabilizes, while free nitrogen effect continues to slowly vanish. However, even though the total stabilizing effect has to finally converge to the pure solvation effect at $0 \% \mathrm{~N}$ limit, the synergy component shows no clear evidence of fading over the considered nitrogen concentration range.

\subsection{Increasing dimensionality}

Computational approach to catalyst modeling often requires reduction of the real system size or dimensionality due to limited computational resources. This approach usually leads to meaningful results due to locality of adsorption phenomena [50], although it may be a source of errors. Here we estimate inaccuracy of the description of real 3-dimensional (N-graphene or N-graphite)/water interface by a 2-dimensional model. This is done by applying three different modifications, one at a time, to the base system, which is a single N-graphene + single water layer. The modifications are: (i) increasing the number of water layers (up to three) on the adsorbate side, (ii) including up to three $\mathrm{N}$-graphene layers and (iii) including water layer on the other side of the N-graphene sheet. 


\subsubsection{Additional water layers on the adsorbate side}

ORR intermediate adsorption and solvation energies for different models of solvation are summarized in Fig. 3. Adding a second water layer on the adsorbate side destabilizes all ORR adsorbates relative to single water layer model. This is likely due to high stability of the reference, where water molecules adopt a special configuration with twice as many interlayer hydrogen bonds as in case of hexagonal ice, as shown in Fig. S3a (Supporting Information). The configuration is preserved to a large extent in systems with ${ }^{*} \mathrm{OH}$ and ${ }^{*} \mathrm{OOH}$ adsorbates (Fig. S3c and S3d), but differs significantly in $* \mathrm{O}$ and $* \mathrm{O}_{2}$ systems (Fig. S3b and $\mathrm{S} 3 \mathrm{e}$ ), resulting in poor stabilization of the last two adsorbates. This special configuration of two water layers has been observed experimentally on graphene in ultrahigh vacuum [51], but is not expected to appear in experimental ORR setups, where the catalyst is immersed in a bulk electrolyte.

With 3 water layers, ORR adsorbate stability is similar to simulations with a single water layer within $0.11 \mathrm{eV}$. Although such differences may sometimes be non-negligible for ORR modeling, we can still conclude that the first water layer has a decisive influence on the adsorbate solvation effects. A single water layer seems to be a reasonable compromise between accuracy and computational cost.

As discussed previously, in the single water layer model the $\mathrm{H}_{2} \mathrm{O} / * \mathrm{O}$ ratio influences $* \mathrm{O}$ solvation energy (Fig. 2). For example, increasing $\mathrm{H}_{2} \mathrm{O} /{ }^{*} \mathrm{O}$ ratio from 5 to 15 increases $\Delta_{\mathrm{stab}}^{\mathrm{W}} E(\mathrm{O})$ from 0.38 to $0.64 \mathrm{eV}$. Similar increase of $\mathrm{H}_{2} \mathrm{O} / * \mathrm{O}$ ratio can be achieved by increasing the number of water layers from one $\left(5 \mathrm{H}_{2} \mathrm{O} /{ }^{*} \mathrm{O}\right)$ to three $\left(17 \mathrm{H}_{2} \mathrm{O} / * \mathrm{O}\right)$. Interestingly, $\Delta_{\text {stab }}^{\mathrm{W}} E(\mathrm{O})$ re- 
mains essentially constant in this process (0.38 and $0.36 \mathrm{eV}$, respectively). This suggests that from the practical point of view the effect of $\mathrm{H}_{2} \mathrm{O} / * \mathrm{O}$ ratio on solvation energy is limited to the first water layer.

\subsubsection{Adding more $N$-graphene layers}

Energetically, the most favorable stacking of multiple N-graphene layers containing $4.2 \% \mathrm{~N}$ is AA stacking with nitrogen atoms located one above another. For this case, BEEF-vdW functional predicts similar (within $0.05 \AA$ ) interlayer distance as for graphite in the AB stacking. The adsorption and solvation energies for systems with single and multiple layers of N-graphene are summarized in Fig. S4 (Supplementary Information). All solvation energies, as well as $\mathrm{OH}$ and $\mathrm{OOH}$ adsorption energies, are not affected by the presence of additional N-graphene layers. However, atomic and molecular oxygen adsorption energies exhibit non-monotonic variations with increasing number of N-graphene layers. Atomic oxygen binding becomes stronger by 0.08 and $0.06 \mathrm{eV}$, while molecular oxygen binding becomes weaker by 0.20 and $0.10 \mathrm{eV}$, for 2 and 3 graphene layers, respectively.

\subsubsection{Water layer on both sides of $N$-graphene}

Including water layer on both sides of $\mathrm{N}$-graphene sheet marginally changes the ${ }^{*} \mathrm{O},{ }^{*} \mathrm{OH}$ and $* \mathrm{OOH}$ adsorption energy relative to having single water layer on the adsorbate side only (Fig. 3). The only affected ORR interme-

diate is $\mathrm{O}_{2}$, which binding energy weakens by about $0.13 \mathrm{eV}$. Though not dramatic, this effect should be remembered while modeling oxygen reduction reaction, as it is unlikely to have vacuum on one side of $2 \mathrm{D}$ catalyst in experimental conditions. 


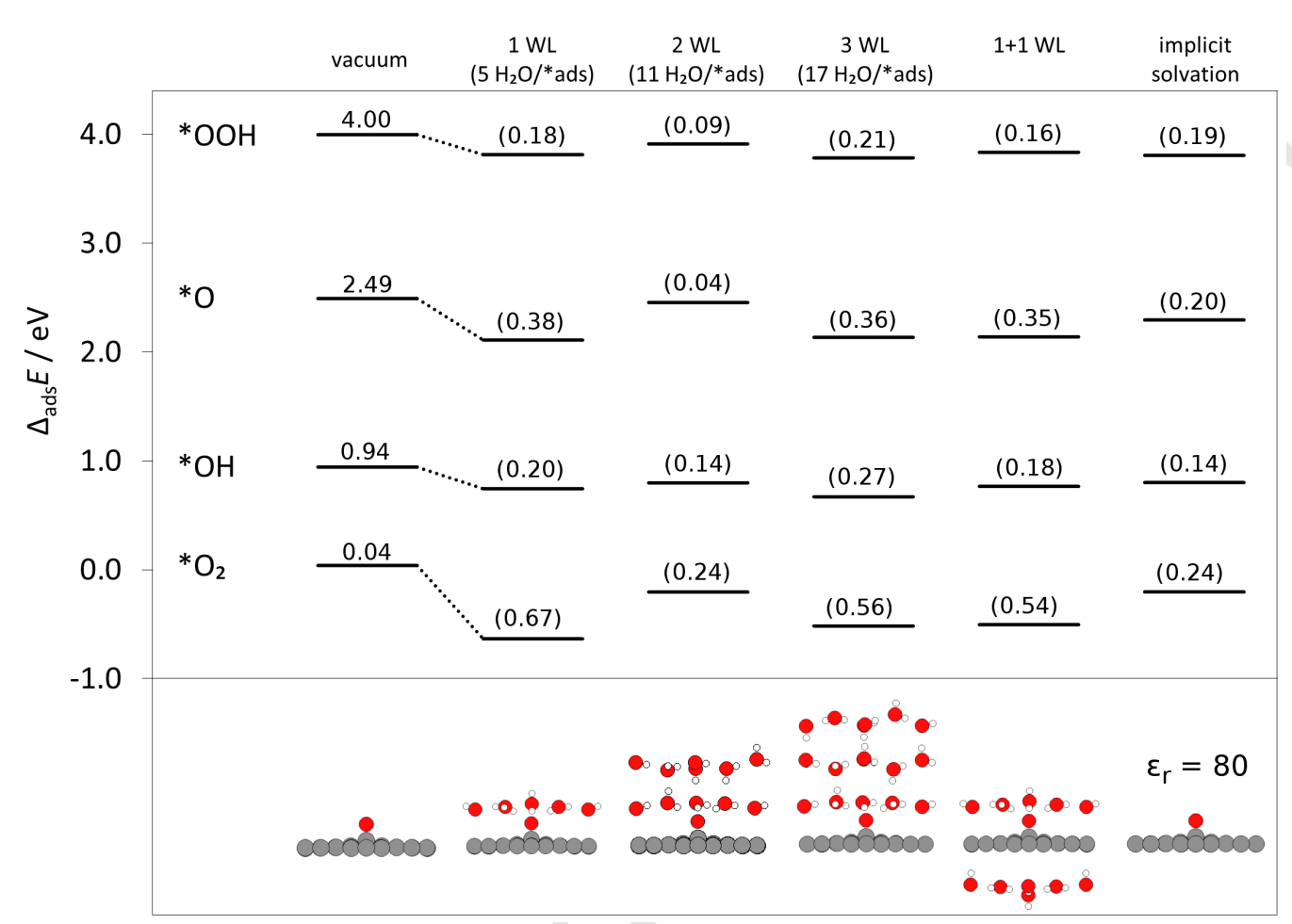

Figure 3: ORR intermediate adsorption energies for different solvation models: 1 to 3 water layers (WL), one water layer on each side, and continuum solvation model. Adsorption energies and stabilization $\left(\Delta_{\mathrm{stab}}^{\mathrm{W}} E(\mathrm{X})\right.$, in brackets) are included in $\mathrm{eV}$ above each $\Delta_{\text {ads }} E$ level. N-graphene models are: $\mathrm{NG}_{-} 12.5 \% \_3 \mathrm{~N} /$ ads for $\mathrm{O}_{2}$ and $\mathrm{NG}_{-} 4.2 \% \_1 \mathrm{~N} /$ ads for $* \mathrm{O}$, ${ }^{*} \mathrm{OH}$ and ${ }^{*} \mathrm{OOH}$. Side-view structures of ${ }^{*} \mathrm{O}$ systems are included below the plot. Color code for atoms: gray - carbon, red - oxygen, white - hydrogen.

\section{Discussion}

In this section we provide an insight into the origin of strong $* \mathrm{O}$ and $* \mathrm{O}_{2}$ stabilization by free nitrogen and solvation effects. We also provide a case study of the oxygen reduction reaction on $\mathrm{N}$-doped graphene with $6.25 \% \mathrm{~N}$ to demonstrate how our findings affect predicted catalyst activity. 
Fig. 4, showing the density of states projected onto adsorbed oxygen sp states for ${ }^{*} \mathrm{O}$ systems, forms the basis for the discussion. It illustrates that free nitrogen (transition from Fig. 4a to 4b) and water (Fig. 4a $\rightarrow$ 4c) cause $\mathrm{O}(\mathrm{sp})$ band filling. When both effects cooperate, essentially all the $\mathrm{O}(\mathrm{sp})$ states are located below the Fermi level.
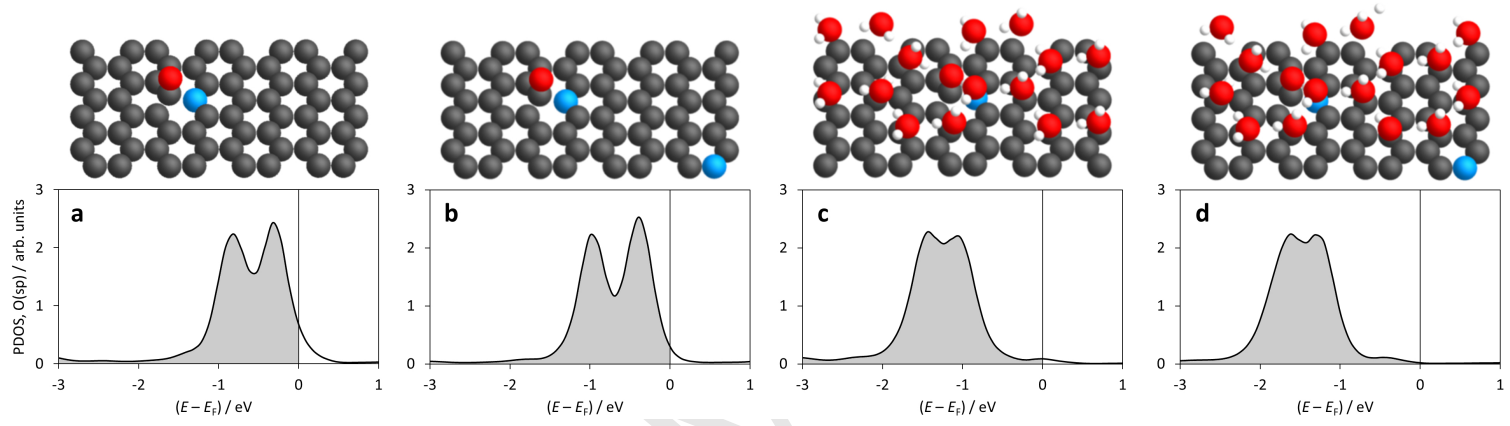

Figure 4: Adsorbed oxygen projected density of states for: (a) $\mathrm{NG}_{-} 1.6 \% \_1 \mathrm{~N} / \mathrm{O}$, (b) NG_3.1\%_2N/O, (c) NG_1.6\%_1N/O/15H $\mathrm{H}_{2} \mathrm{O}$, (d) NG_3.1\%_2N/O/15H $\mathrm{H}_{2} \mathrm{O}$. The corresponding structures are included above the plots. Color code for atoms is the same as in Fig. 2.

\subsection{Stabilization due to free nitrogen}

Free nitrogen selectively stabilizes $* \mathrm{O}$ and $* \mathrm{O}_{2}$. Both adsorbates have one dangling bond, since carbon, which is already bound to three other atoms, can provide only a single bond to oxygen. It is illustrated as unfilled $\mathrm{O}(\mathrm{sp})$ states (Fig. 4a), which makes $* \mathrm{O}$ and ${ }^{*} \mathrm{O}_{2}$ quite reactive and unstable. The presence of free nitrogen in the system significantly stabilizes both adsorbates. In what follows, we study this effect on the example of the *O adsorbate.

Fig. 5 shows the Bader charge on oxygen and nitrogen for $* \mathrm{O}$ systems with and without free nitrogen, as well as the Bader charge on nitrogen in 
a pristine N-graphene sheet. It can be seen that a free nitrogen (Fig. 5b) causes the electron density on oxygen to raise by about $0.06 \mathrm{e}^{-}$, compared to the system without free nitrogen (Fig. 5a). One possible reason for this increase could be electron density transfer from the introduced free nitrogen to oxygen via an inductive and/or mesomeric effect. In that case, we should see electron density depletion on free nitrogen. However, Fig. 5c shows that this does not occur, and the Bader charge on nitrogen in the absence of any adsorbate is the same as the charge on free nitrogen in the presence of ${ }^{*} \mathrm{O}$. We therefore propose another explanation, i.e. that a free nitrogen disrupts graphene's stable aromatic structure, which allows the more electronegative oxygen atom to withdraw electrons from the graphene carbon atoms more effectively.

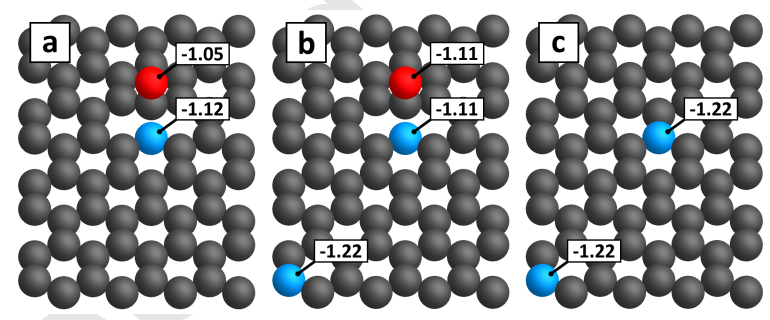

Figure 5: Bader charge on atoms in: (a) NG_1.6_1N/O, (b) NG_3.1_2N/O and (c) NG_3.1. Color code for atoms is the same as in Fig. 2.

The additional electron density on oxygen continues to fill non-fully occupied sp band (Fig. 4b). The system becomes more strongly polarized: oxygen gains negative charge and graphene carbon atoms become positively charged. This shows that, as graphene loses electrons in favor of oxygen, the system becomes partly ionic, while at the same time retaining covalent bonds between respective parts, like in the case of zwitterions. We suggest 
variations in the Coulomb interaction between these parts (ions) are partly responsible for the variations in the stability of oxygen on the surface.

We find a correlation between the average Bader charge on oxygen and average oxygen binding energy for a set of $\mathrm{NG}_{-} 6.25 \%$ systems with varying $\mathrm{N} /{ }^{*} \mathrm{O}$ ratio (Fig. 6). In this case, the charge on oxygen is a measure of charge separation (varied by $\mathrm{N} / * \mathrm{O}$ ratio), while constant nitrogen concentration assures approximately constant distance between centers of positive and negative charges. The figure shows that the larger the charge donation into the $\mathrm{O}(\mathrm{sp})$ states, the more stable the system. We also note that above 2-3 $\mathrm{N} /{ }^{*} \mathrm{O}$ ratio, oxygen can no longer withdraw more electrons from the $\mathrm{N}$-graphene sheet, and its adsorption energy stabilizes with respect to the number of free nitrogen atoms, as shown previously in Fig. 1.

It is worth noting that even though ${ }^{*} \mathrm{O}$ binding energy correlates with Bader charge on oxygen at a constant nitrogen concentration, these two properties do not correlate in general. For example, the Bader charge on oxygen is approximately constant $(-1.10 \pm 0.01)$ for the systems forming $2 \mathrm{~N} /{ }^{*} \mathrm{O}$ curve in Fig. 2, where the nitrogen concentration changes. In light of the proposed explanation, the observed decrease of the oxygen binding with decreasing nitrogen concentration is caused by the increase of the distance between fixed-charge ions. This dependence studied over a broader range of nitrogen concentrations reveals its hyperbolic character (Fig. S1, Supporting Information), which is expected for electrostatically interacting system. 


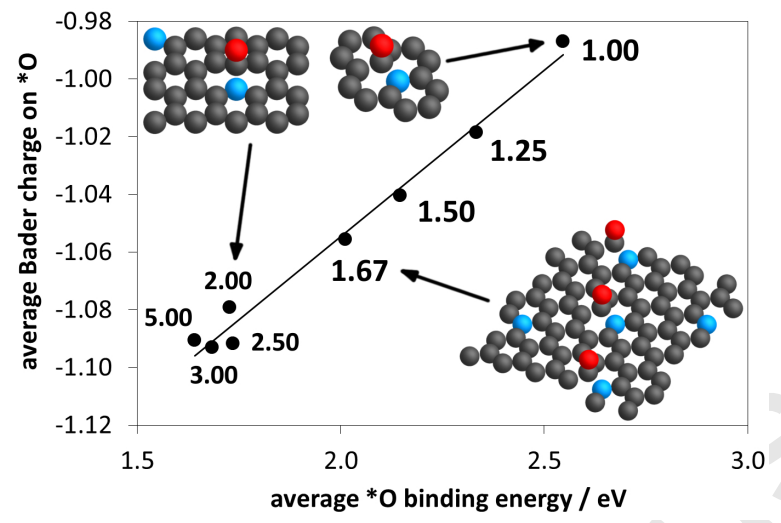

Figure 6: Average $\Delta_{\text {ads }} E(\mathrm{O})$ vs. average Bader charge on ${ }^{*} \mathrm{O}$ at different $\mathrm{N} /{ }^{*} \mathrm{O}$ ratios for a set of NG_6.25\% systems. Color code for atoms is the same as in Fig. 2.

\subsection{Stabilization due to water}

Water stabilizes all the ORR intermediates (Fig. 3). However, its influence on ${ }^{*} \mathrm{O}$ and ${ }^{*} \mathrm{O}_{2}$ is clearly stronger than on ${ }^{*} \mathrm{OH}$ and ${ }^{*} \mathrm{OOH}$. As noted previously, the difference between these two groups of adsorbates lies in occupation of $\mathrm{O}(\mathrm{sp})$ states. ${ }^{*} \mathrm{O}$ and ${ }^{*} \mathrm{O}_{2}$ have empty states, and their reactivity is thus much higher than that of $* \mathrm{OH}$ or $* \mathrm{OOH}$.

The strong stabilizing effect of water on atomic and molecular oxygen can be explained by bond formation between water molecules and adsorbed species. In this process, water fills oxygen empty states, as can be seen from location of $\mathrm{O}(\mathrm{sp})$ band relative to Fermi level in vacuum (Fig. 4a and 4b) and in water (Fig. 4c and 4d). Bonds formed between $* \mathrm{O}$ and $\mathrm{H}_{2} \mathrm{O}$ are about $0.18 \AA$ shorter (average of three bonds) than hydrogen bonds between water and $* \mathrm{OH}$, suggesting they are much stronger than regular hydrogen bonds.

Describing water as a continuum polarizable medium $\left(\varepsilon_{\mathrm{r}}=80\right)$ results in unsatisfactory ${ }^{*} \mathrm{O}$ and ${ }^{*} \mathrm{O}_{2}$ stabilization energies. For the system with 
low $\mathrm{H}_{2} \mathrm{O} / *$ ads ratio considered in Fig. 3, implicit solvation underestimates $\Delta_{\text {stab }}^{\mathrm{W}} E(\mathrm{O})$ and $\Delta_{\mathrm{stab}}^{\mathrm{W}} E\left(\mathrm{O}_{2}\right)$ by 0.18 and $0.43 \mathrm{eV}$, respectively, relative to solvation by a single water layer. The situation becomes even worse for systems with higher $\mathrm{H}_{2} \mathrm{O} / *$ ads ratio (e.g. underestimation of $* \mathrm{O}$ solvation by $0.40 \mathrm{eV}$ in $\mathrm{NG}_{-} 4.2 \% \_2 \mathrm{~N} / \mathrm{O} / 11 \mathrm{H}_{2} \mathrm{O}$ system). At the same time, implicit water reproduces ${ }^{*} \mathrm{OH}$ and $* \mathrm{OOH}$ solvation with deviations smaller than $0.1 \mathrm{eV}$. Continuum solvation models can capture polarization effects in the system, but since they neglect granular structure of the solvent, they cannot describe all the solvent-adsorbate interactions. This confirms that wateroxygen bond formation contributes significantly to $* \mathrm{O}$ and ${ }^{*} \mathrm{O}_{2}$ stabilization. It also means that implicit solvation is not particularly suitable for ORR modeling on N-doped graphene.

Interestingly, the effect of strong *O solvation appears not to be limited to basal plane N-doped graphene. As long as the atomic oxygen is located in atop adsorption site, significant ${ }^{*} \mathrm{O}$ stabilization (via solvation) energies of $0.5-1.2 \mathrm{eV}$ are found on other types of materials, such as: Bdoped graphene, N-doped graphene with Stone-Wales defect, $\mathrm{Fe}_{3} \mathrm{C}$-supported graphene, hydrogen-terminated graphite step zigzag edges (non-basal plane carbon material) and hexagonal boron nitride (non-carbon material). The structures and $* O$ stabilization energies for these systems can be found in Tab. S1, Supporting Information. In all these cases, atop oxygen can form only a single bond with $2^{\text {nd }}$ row element $(\mathrm{C}$ or $\mathrm{B})$, which is already bound to 3 other atoms. High stabilization energy can be explained by water-oxygen bond formation, like in the case of basal plane N-doped graphene. 


\subsection{Case study: ORR on $N$-graphene (6.25\%N) with explicit water}

To demonstrate how our findings affect predicted ORR activity, we take the example of $\mathrm{N}$-doped graphene at $6.25 \% \mathrm{~N}$. We assume associative ORR pathway and neglect $* \mathrm{O}_{2}$ intermediate, as there is a strong evidence suggesting that the molecular oxygen adsorption is not necessarily required for the ORR to occur on N-doped graphene [52].

We first take a simple N-graphene model with one nitrogen and 15 carbon atoms in the unit cell, and 4 water molecules in single water layer $\left(\mathrm{NG}_{-} 6.25 \% \_1 \mathrm{~N} / \mathrm{ads} / 4 \mathrm{H}_{2} \mathrm{O}\right)$. Its structure and free energy diagram at 0.8 $\mathrm{V}_{\mathrm{RHE}}$ is shown in Fig. 7a. This system represents the simplest N-graphene/water interface model, that could be used for ORR modeling at this nitrogen concentration. The predicted thermodynamic overpotential is $0.78 \mathrm{~V}$. However, this model is relevant for ORR modeling only under the assumption that adsorbate binding energies do not depend on coverage $\left(\theta_{\text {ads }}\right)$. While this is true for $* \mathrm{OH}$ and $* \mathrm{OOH}$ adsorbates, at low $* \mathrm{O}$ coverage (or, equivalently, high $\mathrm{N} /{ }^{*} \mathrm{O}$ ratio), atomic oxygen binds at least $0.8 \mathrm{eV}$ stronger than at $\theta_{\text {ads }}=1$ (Fig. 1). This will cause some nitrogen atoms in adjacent cells will tend to remain free for the ${ }^{*} \mathrm{O}$ system to achieve a lower energy structure.

In the second step, we consider a $(\sqrt{2} \times \sqrt{2})$ version of the previous cell, and all the ORR steps occurring in the presence of a free nitrogen $\left(\theta_{\text {ads }}=1 / 2\right)$. The structure and the free energy diagram for this system are shown in Fig. 7b. This time ${ }^{*} \mathrm{O}$ binds so strong that its protonation becomes the potential-determining step. The resulting thermodynamic overpotential is $1.14 \mathrm{~V}$.

Further increase of the $\mathrm{N} / *^{*}$ ads ratio results in even more stable ${ }^{*} \mathrm{O}$, with 
practically no change of the ${ }^{*} \mathrm{OH}$ and ${ }^{*} \mathrm{OOH}$ levels (see Fig. 1). It suggests that some amount of ${ }^{*} \mathrm{O}$ will be present on the catalyst surface throughout the entire oxygen reduction process in the form of ${ }^{*} \mathrm{O}$ spectators. Atomic oxygen stability starts to decrease for $\mathrm{N} /{ }^{*} \mathrm{O}<2$ as shown in Fig. 6. Entering that range would increase $* \mathrm{O}$ free energy in Fig. $7 \mathrm{~b}$, such that $* \mathrm{O}$ protonation may no longer be a potential-determining step. In other words, increasing $* \mathrm{O}$ coverage above $1 / 2$ allows the catalyst to explore free energy paths with lower overall thermodynamic barriers. We therefore suggest that, at $6.25 \% \mathrm{~N}$, the oxygen reduction reaction occurs on basal plane $\mathrm{N}$-doped graphene at ${ }^{*} \mathrm{O}$ coverages not lower than $1 / 2$.

On the other hand, the coverage cannot be too close to 1. For example, introducing an $* \mathrm{O}$ spectator in the $(\sqrt{2} \times \sqrt{2})$ cell leaves only one catalytic site where the oxygen reduction reaction can take place, resulting in $\theta_{\text {ads }}=1$. Adsorption of any ORR intermediate in such a position is highly unfavorable, as it significantly destabilizes spectator ${ }^{*} \mathrm{O}$, which can no longer take the advantage of the free nitrogen effect (which is about $0.8 \mathrm{eV}$ at $6.25 \% \mathrm{~N}$, see Fig. 1). As a consequence, in order to minimize the barriers along the ORR free energy diagram, the system seeks to adopt a configuration in which both the ${ }^{*} \mathrm{O}$ and free nitrogen are simultaneously present in the catalytic environment.

Summarizing, the optimal adsorbate coverage is in the range of $1 / 2<$ $\theta_{\text {ads }}<1$. The simplest realization of this scenario is a N-graphene cell containing three nitrogen atoms. A carbon near the first of the $\mathrm{N}$ atoms is permanently bound with atomic oxygen, the second $\mathrm{N}$ atom is free throughout the process, and a carbon near the third $\mathrm{N}$ serves as an adsorption site 
for ORR intermediates. The reaction occurs here at $\theta_{\text {ads }}=2 / 3$. The free energy diagram an the catalyst structure with ${ }^{*} \mathrm{OH}$ adsorbate is shown in Fig. 7c. The thermodynamic overpotential is found to be $0.94 \mathrm{~V}$, with potential-determining step being the ${ }^{*} \mathrm{OOH}$ formation on the surface. 

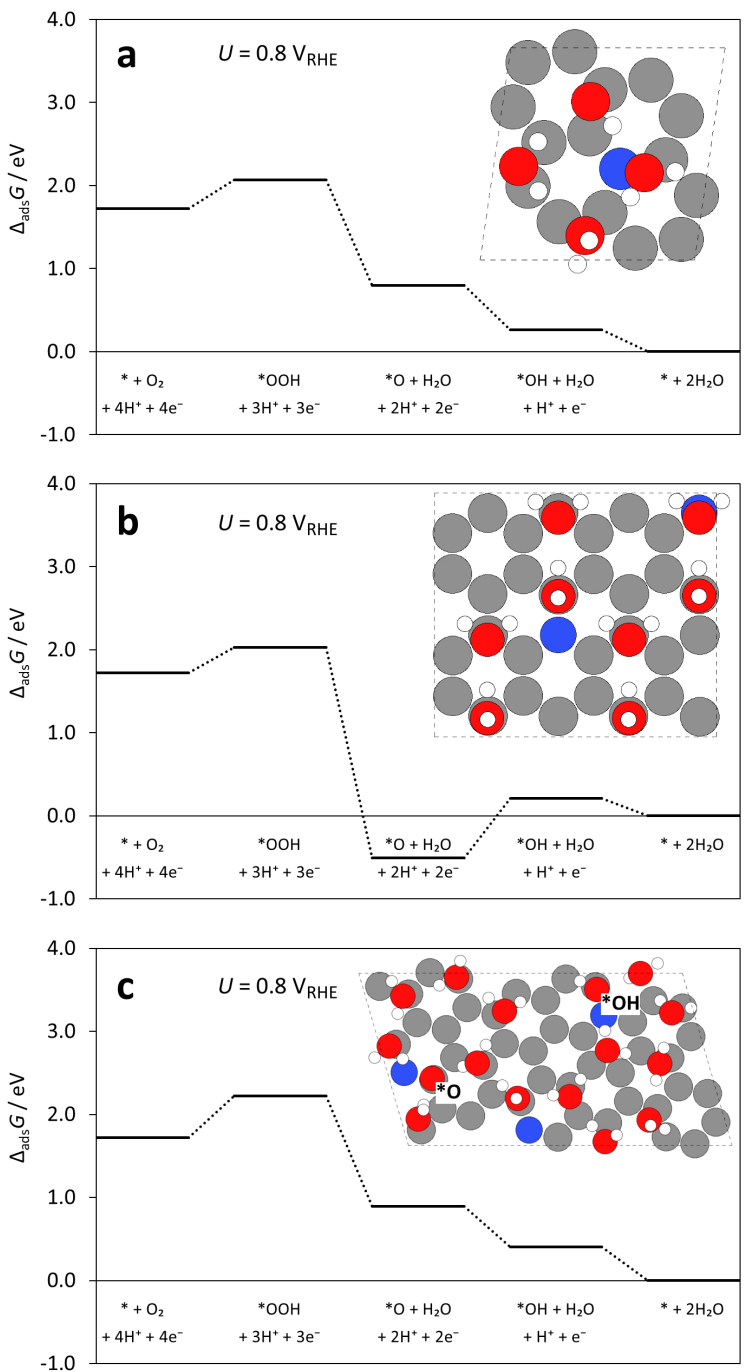

Figure 7: Oxygen reduction reaction free energy diagrams at $U=0.8 \mathrm{~V}_{\mathrm{RHE}}$ for $\mathrm{N}$-graphene $(6.25 \% \mathrm{~N})$ : (a) one $\mathrm{N}$ atom in the unit cell; ORR occurs at $\theta_{\text {ads }}=1$; inset shows the structure of a pristine catalyst, (b) two $\mathrm{N}$ atoms in the unit cell; ORR occurs at $\theta_{\text {ads }}=1 / 2$; inset shows the structure of a pristine catalyst, (c) three $\mathrm{N}$ atoms in the unit cell; one adsorbed atomic oxygen and one free nitrogen act as spectators; ORR occurs at $\theta_{\text {ads }}=2 / 3$; inset shows the structure of $* \mathrm{OH}$ in the catalytic environment defined by the spectators and a single water layer. Color code for atoms: gray - carbon, blue - nitrogen, red oxygen, white - hydrogen. 
It has to be noted that the predicted thermodynamic overpotential refers to the particular model studied here. In real systems, the distribution of nitrogen does not have to be regular, and nitrogen clustering may be observed. It is likely that there exist different adsorbate coverages and different $\left({ }^{*} \mathrm{O}\right.$ spectator + free nitrogen + catalytic site $)$ configurations, which result in lower thermodynamic barrier for the ORR, and thus dominate the basal plane N-doped graphene activity towards the oxygen reduction.

\section{Conclusions}

Two effects are found to be responsible for the unusually high stabilization of $* \mathrm{O}$ and $* \mathrm{O}_{2}$ adsorbates on basal plane $\mathrm{N}$-doped graphene compared to conventional metal-based ORR catalysts. These have been systematically studied here, i.e. the effect of additional, free nitrogen in the N-graphene sheet, and the solvation effect. The total stabilization from these two effects reaches values as high as $1.5 \mathrm{eV}$, including a $0.17 \mathrm{eV}$ synergy component. Both effects are found to result from the high reactivity of $* \mathrm{O}$ and ${ }^{*} \mathrm{O}_{2}$ adsorbates, caused by the presence of dangling bonds, which manifest themselves as unoccupied $\mathrm{O}(\mathrm{sp})$ states. Variations in the ${ }^{*} \mathrm{O}$ binding energy due to free nitrogen exhibit a long-range character, resembling electrostatic $1 / r$ interactions between the charged parts of the system. The solvation effect is likely to be universal for materials where oxygen adsorbs on a $2^{\text {nd }}$ row element in the atop position.

A case study of the oxygen reduction reaction at $6.25 \% \mathrm{~N}$ shows that the reaction occurs at an adsorbate surface coverage between $1 / 2<\theta_{\text {ads }}<1$, in the presence of $* \mathrm{O}$ and free nitrogen spectators. 
Including explicit $\mathrm{H}_{2} \mathrm{O}$ molecules is essential for correct description of ORR intermediates adsorption energy on carbon materials. Continuum solvation models are unable to describe solvation of ${ }^{*} \mathrm{O}$ and ${ }^{*} \mathrm{O}_{2}$ with sufficient accuracy, likely due to bond formation between these adsorbates and surrounding water molecules. We find that the first water layer has decisive influence on the adsorbate solvation. Including a single water layer to account for solvation effects seems to be a reasonable compromise between accuracy and computational cost.

\section{Acknowledgements}

The authors would like to thank the Innovation Fund Denmark for funding through the Initiative Towards Non-Precious Metal Polymer Fuel Cells (NonPrecious), project no. 4106-00012A, as well as The Velux Foundations through the research center V-Sustain (Grant 9455). One of us (MR) would like to thank Colin F. Dickens (Stanford University) for fruitful discussions.

\section{References}

[1] G. Crabtree, M. Dresselhaus, The hydrogen fuel alternative, MRS Bull. 33 (4) (2008) 421-428. doi:10.1557/mrs2008.84.

URL https://www . cambridge.org/core/article/ div-class-title-hydrogen-fuel-alternative-div/ BFD3D2EBB36FEA8BDBDD539D537D616B

[2] E. Callini, K.-F. Aguey-Zinsou, R. Ahuja, J. R. Ares, S. Bals, N. Biliškov, S. Chakraborty, G. Charalambopoulou, A.-L. Chaudhary, F. Cuevas, B. Dam, P. de Jongh, M. Dornheim, Y. Filinchuk, J. G. 
Novaković, M. Hirscher, T. R. Jensen, P. B. Jensen, N. Novaković, Q. Lai, F. Leardini, D. M. Gattia, L. Pasquini, T. Steriotis, S. Turner, T. Vegge, A. Züttel, A. Montone, Nanostructured materials for solid-state hydrogen storage: A review of the achievement of COST action MP1103, Int. J. Hydrogen Energy 41 (32) (2016) 14404-14428. doi:http://dx.doi.org/10.1016/j.ijhydene.2016.04.025.

URL

//www.sciencedirect.com/science/article/pii/ S0360319915319182

[3] Y. Nie, L. Li, Z. Wei, Recent advancements in Pt and Pt-free catalysts for oxygen reduction reaction, Chem. Soc. Rev. 44 (2015) 2168-2201. doi:10.1039/C4CS00484A.

URL http://dx.doi.org/10.1039/C4CS00484A

[4] V. R. Stamenkovic, B. S. Mun, M. Arenz, K. J. J. Mayrhofer, C. A. Lucas, G. Wang, P. N. Ross, N. M. Markovic, Trends in electrocatalysis on extended and nanoscale Pt-bimetallic alloy surfaces, Nat. Mater. 6 (3) (2007) 241-247. doi:10.1038/nmat1840.

URL http://dx.doi.org/10.1038/nmat1840

[5] R. Othman, A. L. Dicks, Z. Zhu, Non precious metal catalysts for the PEM fuel cell cathode, International Journal of Hydrogen Energy 37 (1) (2012) 357-372, 11th China Hydrogen Energy Conference. doi:http://dx.doi.org/10.1016/j.ijhydene.2011.08.095.

URL http://www.sciencedirect.com/science/article/pii/ S0360319911020192

[6] D. C. Higgins, Z. Chen, Recent progress in non-precious metal catalysts 
for PEM fuel cell applications, Can. J. Chem. Eng. 91 (12) (2013) 18811895. doi:10.1002/cjce.21884.

URL http://dx.doi.org/10.1002/cjce.21884

[7] L. Dai, Y. Xue, L. Qu, H.-J. Choi, J.-B. Baek, Metal-free catalysts for oxygen reduction reaction, Chem. Rev. 115 (11) (2015) 4823-4892, pMID: 25938707. arXiv:http://dx.doi.org/10.1021/cr5003563, doi: $10.1021 / \operatorname{cr} 5003563$.

URL http://dx.doi.org/10.1021/cr5003563

[8] D. Higgins, P. Zamani, A. Yu, Z. Chen, The application of graphene and its composites in oxygen reduction electrocatalysis: a perspective and review of recent progress, Energy Environ. Sci. 9 (2016) 357-390. doi : 10.1039/C5EE02474A.

URL http://dx.doi.org/10.1039/C5EE02474A

[9] W. Xia, A. Mahmood, Z. Liang, R. Zou, S. Guo, Earth-abundant nanomaterials for oxygen reduction, Angew. Chem. Int. Ed. 55 (8) (2016) 2650-2676. doi:10.1002/anie.201504830.

URL http://dx.doi.org/10.1002/anie. 201504830

[10] E. Proietti, F. Jaouen, M. Lefèvre, N. Larouche, J. Tian, J. Herranz, J.-P. Dodelet, Iron-based cathode catalyst with enhanced power density in polymer electrolyte membrane fuel cells, Nat. Commun. 2 (2011) 416. doi:10.1038/ncomms1427.

URL http://dx.doi.org/10.1038/ncomms 1427

[11] G. Wu, K. L. More, C. M. Johnston, P. Zelenay, High-performance 
electrocatalysts for oxygen reduction derived from polyaniline, iron, and cobalt, Science 332 (6028) (2011) 443-447. arXiv: http://www.sciencemag.org/content/332/6028/443.full.pdf, doi:10.1126/science.1200832.

URL http://www.sciencemag.org/content/332/6028/443. abstract

[12] W. A. Saidi, Oxygen reduction electrocatalysis using N-doped graphene quantum-dots, J. Phys. Chem. Lett. 4 (23) (2013) 4160-4165. arXiv: http://dx.doi.org/10.1021/jz402090d, doi:10.1021/jz402090d. URL http://dx.doi.org/10.1021/jz402090d

[13] D. Kwak, A. Khetan, S. Noh, H. Pitsch, B. Han, First principles study of morphology, doping level, and water solvation effects on the catalytic mechanism of nitrogen-doped graphene in the oxygen reduction reaction, ChemCatChem 6 (9) (2014) 2662-2670. doi:10.1002/cctc. 201402248.

URL http://dx.doi.org/10.1002/cctc. 201402248

[14] G.-L. Chai, Z. Hou, D.-J. Shu, T. Ikeda, K. Terakura, Active sites and mechanisms for oxygen reduction reaction on nitrogen-doped carbon alloy catalysts: Stone-Wales defect and curvature effect, J. Am. Chem. Soc. 136 (39) (2014) 13629-13640. arXiv:http://dx.doi.org/ 10.1021/ja502646c, doi:10.1021/ja502646c.

URL http://dx.doi.org/10.1021/ja502646c

[15] J. W. F. To, J. W. D. Ng, S. Siahrostami, A. L. Koh, Y. Lee, Z. Chen, K. D. Fong, S. Chen, J. He, W.-G. Bae, J. Wilcox, H. Y. Jeong, 
K. Kim, F. Studt, J. K. Nørskov, T. F. Jaramillo, Z. Bao, Highperformance oxygen reduction and evolution carbon catalysis: From mechanistic studies to device integration, Nano Res. 10 (4) (2017) 11631177. doi:10.1007/s12274-016-1347-8.

URL http://dx.doi.org/10.1007/s12274-016-1347-8

[16] A. Ferre-Vilaplana, E. Herrero, Charge transfer, bonding conditioning and solvation effect in the activation of the oxygen reduction reaction on unclustered graphitic-nitrogen-doped graphene, Phys. Chem. Chem. Phys. 17 (2015) 16238-16242. doi:10.1039/C5CP00918A.

URL http://dx.doi.org/10.1039/C5CP00918A

[17] L. Yu, X. Pan, X. Cao, P. Hu, X. Bao, Oxygen reduction reaction mechanism on nitrogen-doped graphene: A density functional theory study, J. Catal. 282 (1) (2011) 183-190. doi:10.1016/j.jcat.2011.06.015. URL http://www.sciencedirect.com/science/article/pii/ S0021951711002016

[18] F. Studt, The oxygen reduction reaction on nitrogen-doped graphene, Catal. Lett. 143 (1) (2013) 58-60. doi:10.1007/s10562-012-0918-x. URL http://dx.doi .org/10.1007/s10562-012-0918-x

[19] G. Henkelman, A. Arnaldsson, H. J'onsson, A fast and robust algorithm for bader decomposition of charge density, Comput. Mater. Sci. 36 (3) (2006) 354-360. doi:10.1016/j.commatsci.2005.04.010.

URL http://www.sciencedirect.com/science/article/pii/ S0927025605001849 
[20] S. R. Bahn, K. W. Jacobsen, An object-oriented scripting interface to a legacy electronic structure code, Comput. Sci. Eng. 4 (3) (2002) 56-66. doi:10.1109/5992.998641.

URL http://ieeexplore.ieee.org/document/998641/

[21] G. Kresse, J. Hafner, Ab initio molecular dynamics for liquid metals, Phys. Rev. B 47 (1993) 558-561. doi:10.1103/PhysRevB.47.558.

URL http://link.aps.org/doi/10.1103/PhysRevB.47.558

[22] G. Kresse, J. Hafner, Ab initio molecular-dynamics simulation of the liquid-metal-amorphous-semiconductor transition in germanium, Phys. Rev. B 49 (1994) 14251-14269. doi:10.1103/PhysRevB.49.14251.

URL http://link.aps.org/doi/10.1103/PhysRevB.49.14251

[23] G. Kresse, J. Furthmüller, Efficiency of ab-initio total energy calculations for metals and semiconductors using a planewave basis set, Comput. Mater. Sci. 6 (1) (1996) 15-50. doi : 10.1016/0927-0256(96)00008-0.

URL http://www.sciencedirect.com/science/article/pii/ 0927025696000080

[24] G. Kresse, J. Furthmüller, Efficient iterative schemes for ab initio totalenergy calculations using a plane-wave basis set, Phys. Rev. B 54 (1996) 11169-11186. doi:10.1103/PhysRevB.54.11169.

URL http://link.aps.org/doi/10.1103/PhysRevB.54.11169

[25] P. E. Blöchl, Projector augmented-wave method, Phys. Rev. B 50 (1994) 
17953-17979. doi:10.1103/PhysRevB.50.17953.

URL http://link.aps.org/doi/10.1103/PhysRevB.50.17953

[26] G. Kresse, D. Joubert, From ultrasoft pseudopotentials to the projector augmented-wave method, Phys. Rev. B 59 (1999) 1758-1775. doi:10. 1103/PhysRevB.59.1758.

URL http://link.aps.org/doi/10.1103/PhysRevB.59.1758

[27] H. J. Monkhorst, J. D. Pack, Special points for Brillouin-zone integrations, Phys. Rev. B 13 (1976) 5188-5192. doi:10.1103/PhysRevB.13. 5188.

URL http://link.aps.org/doi/10.1103/PhysRevB.13.5188

[28] J. P. Perdew, K. Burke, M. Ernzerhof, Generalized gradient approximation made simple, Phys. Rev. Lett. 77 (1996) 3865-3868. doi: 10.1103/PhysRevLett.77.3865.

URL http://link.aps.org/doi/10.1103/PhysRevLett.77.3865

[29] B. Hammer, L. B. Hansen, J. K. Nørskov, Improved adsorption energetics within density-functional theory using revised Perdew-BurkeErnzerhof functionals, Phys. Rev. B 59 (1999) 7413-7421. doi :10.1103/ PhysRevB.59.7413.

URL http://link.aps.org/doi/10.1103/PhysRevB.59.7413

[30] J. Wellendorff, K. T. Lundgaard, A. Møgelhøj, V. Petzold, D. D. Landis, J. K. Nørskov, T. Bligaard, K. W. Jacobsen, Density functionals for surface science: Exchange-correlation model development with Bayesian error estimation, Phys. Rev. B 85 (2012) 235149. doi: 
10.1103/PhysRevB.85.235149.

URL http://link.aps.org/doi/10.1103/PhysRevB.85.235149

[31] K. Lee, E. D. Murray, L. Kong, B. I. Lundqvist, D. C. Langreth, Higheraccuracy van der Waals density functional, Phys. Rev. B 82 (2010) 081101. doi:10.1103/PhysRevB.82.081101.

URL http://link.aps.org/doi/10.1103/PhysRevB.82.081101

[32] J. Wellendorff, T. L. Silbaugh, D. Garcia-Pintos, J. K. Nørskov, T. Bligaard, F. Studt, C. T. Campbell, A benchmark database for adsorption bond energies to transition metal surfaces and comparison to selected DFT functionals, Surf. Sci. 640 (2015) 36-44. doi:10.1016/j.susc.2015.03.023.

URL http://www.sciencedirect.com/science/article/pii/ S0039602815000837

[33] A. J. Medford, J. Wellendorff, A. Vojvodic, F. Studt, F. Abild-Pedersen, K. W. Jacobsen, T. Bligaard, J. K. Nørskov, Assessing the reliability of calculated catalytic ammonia synthesis rates, Science 345 (6193) (2014) 197-200. arXiv:http://science.sciencemag.org/content/ 345/6193/197.full.pdf, doi:10.1126/science.1253486.

URL http://science.sciencemag.org/content/345/6193/197

[34] K. Mathew, R. Sundararaman, K. Letchworth-Weaver, T. A. Arias, R. G. Hennig, Implicit solvation model for density-functional study of nanocrystal surfaces and reaction pathways, J. Chem. Phys. 140 (8) (2014) 084106. doi:10.1063/1.4865107. 
URL http://scitation.aip.org/content/aip/journal/jcp/140/ $8 / 10.1063 / 1.4865107$

[35] K. Mathew, R. G. Hennig, Implicit self-consistent description of electrolyte in plane-wave density-functional theory, arXiv:1601.03346 (2016).

URL http://arxiv.org/abs/1601.03346

[36] S. Goedecker, Minima hopping: An efficient search method for the global minimum of the potential energy surface of complex molecular systems, J. Chem. Phys. 120 (21) (2004) 9911-9917. doi:10.1063/1.1724816. URL http://scitation.aip.org/content/aip/journal/jcp/120/ $21 / 10.1063 / 1.1724816$

[37] A. A. Peterson, Global optimization of adsorbate-surface structures while preserving molecular identity, Top. Catal. 57 (1) (2014) 40-53. doi:10.1007/s11244-013-0161-8.

URL http://dx.doi.org/10.1007/s11244-013-0161-8

[38] J. Rossmeisl, A. Logadottir, J. Nørskov, Electrolysis of water on (oxidized) metal surfaces, Chem. Phys. 319 (1-3) (2005) 178-184. doi:10.1016/j.chemphys.2005.05.038.

URL http://www.sciencedirect.com/science/article/pii/ S0301010405002053

[39] R. Christensen, H. A. Hansen, T. Vegge, Identifying systematic DFT errors in catalytic reactions, Catal. Sci. Technol. 5 (2015) 4946-4949. 
doi:10.1039/C5CY01332A.

URL http://dx.doi.org/10.1039/C5CY01332A

[40] R. Christensen, H. A. Hansen, C. F. Dickens, J. K. Nørskov, T. Vegge, Functional independent scaling relation for ORR/OER catalysts, J. Phys. Chem. C 120 (43) (2016) 24910-24916. arXiv:http://dx.doi. org/10.1021/acs.jpcc.6b09141, doi:10.1021/acs.jpcc.6b09141. URL http://dx.doi.org/10.1021/acs.jpcc.6b09141

[41] D. Yu, Q. Zhang, L. Dai, Highly efficient metal-free growth of nitrogen-doped single-walled carbon nanotubes on plasma-etched substrates for oxygen reduction, J. Am. Chem. Soc. 132 (43) (2010) 15127-15129. arXiv:http://dx.doi.org/10.1021/ja105617z, doi: 10.1021/ja105617z.

URL http://dx.doi.org/10.1021/ja105617z

[42] J. K. Nørskov, J. Rossmeisl, A. Logadottir, L. Lindqvist, J. R. Kitchin, T. Bligaard, H. Jónsson, Origin of the overpotential for oxygen reduction at a fuel-cell cathode, J. Phys. Chem. B 108 (46) (2004) 17886-17892. arXiv:http://dx.doi.org/10.1021/jp047349j, doi: 10.1021/jp047349j.

URL http://dx.doi.org/10.1021/jp047349j

[43] M. H. Hansen, J. Rossmeisl, $\mathrm{pH}$ in grand canonical statistics of an electrochemical interface, J. Phys. Chem. C 120 (51) (2016) 2913529143. arXiv:http://dx.doi.org/10.1021/acs.jpcc.6b09019, doi: 10.1021/acs.jpcc.6b09019. URL http://dx.doi.org/10.1021/acs.jpcc.6b09019 
[44] G. S. Karlberg, J. Rossmeisl, J. K. Nørskov, Estimations of electric field effects on the oxygen reduction reaction based on the density functional theory, Phys. Chem. Chem. Phys. 9 (2007) 5158-5161. doi:10.1039/ B705938H.

URL http://dx.doi.org/10.1039/B705938H

[45] V. Tripković, E. Skúlason, S. Siahrostami, J. K. Nørskov, J. Rossmeisl, The oxygen reduction reaction mechanism on $\operatorname{Pt}\left(\begin{array}{lll}1 & 1 & 1\end{array}\right)$ from density functional theory calculations, Electrochim. Acta 55 (27) (2010) 7975-7981. doi:10.1016/j.electacta.2010.02.056.

URL http://www.sciencedirect.com/science/article/pii/ S0013468610003178

[46] V. Tripkovic, T. Vegge, Potential- and rate-determining step for oxygen reduction on Pt(111), J. Phys. Chem. C 121 (48) (2017) 2678526793. arXiv:http://dx.doi.org/10.1021/acs.jpcc.7b07472, doi: 10.1021/acs.jpcc.7b07472.

URL http://dx.doi.org/10.1021/acs.jpcc.7b07472

[47] R. Koitz, J. K. Nørskov, F. Studt, A systematic study of metalsupported boron nitride materials for the oxygen reduction reaction, Phys. Chem. Chem. Phys. 17 (2015) 12722-12727. doi:10.1039/ C5CP01384D.

URL http://dx.doi.org/10.1039/C5CP01384D

[48] S. Liu, M. G. White, P. Liu, Mechanism of oxygen reduction reaction on $\operatorname{Pt}(111)$ in alkaline solution: Importance of chemisorbed water on surface, J. Phys. Chem. C 120 (28) (2016) 15288-15298. arXiv:http: 
//dx.doi.org/10.1021/acs.jpcc.6b05126, doi:10.1021/acs.jpcc. $6 \mathrm{~b} 05126$.

URL http://dx.doi.org/10.1021/acs.jpcc.6b05126

[49] J. Sun, Y.-H. Fang, Z.-P. Liu, Electrocatalytic oxygen reduction kinetics on Fe-center of nitrogen-doped graphene, Phys. Chem. Chem. Phys. 16 (2014) 13733-13740. doi:10.1039/C4CP00037D.

URL http://dx.doi.org/10.1039/C4CP00037D

[50] L. Li, A. H. Larsen, N. A. Romero, V. A. Morozov, C. Glinsvad, F. Abild-Pedersen, J. Greeley, K. W. Jacobsen, J. K. Nørskov, Investigation of catalytic finite-size-effects of platinum metal clusters, J. Phys. Chem. Lett. 4 (1) (2013) 222-226. arXiv:http://dx.doi.org/ 10.1021/jz3018286, doi:10.1021/jz3018286.

URL http://dx.doi.org/10.1021/jz3018286

[51] G. A. Kimmel, J. Matthiesen, M. Baer, C. J. Mundy, N. G. Petrik, R. S. Smith, Z. Dohnlek, B. D. Kay, No confinement needed: Observation of a metastable hydrophobic wetting two-layer ice on graphene, J. Am. Chem. Soc. 131 (35) (2009) 12838-12844. arXiv:http://dx.doi.org/ 10.1021/ja904708f, doi:10.1021/ja904708f.

URL http://dx.doi.org/10.1021/ja904708f

[52] C. H. Choi, H.-K. Lim, M. W. Chung, J. C. Park, H. Shin, H. Kim, S. I. Woo, Long-range electron transfer over graphene-based catalyst for high-performing oxygen reduction reactions: Importance of size, Ndoping, and metallic impurities, J. Am. Chem. Soc. 136 (25) (2014) 9070-9077, pMID: 24905892. arXiv:http://dx.doi.org/10.1021/ 
ja5033474, doi:10.1021/ja5033474.

URL http://dx.doi.org/10.1021/ja5033474 
- Two stabilizing effects on $\mathrm{N}$-doped graphene are studied systematically by means of the Density Functional Theory.

- The effects of free nitrogen and solvent (water) synergistically stabilize *O adsorbates by up to $1.5 \mathrm{eV}$.

- The effects of free nitrogen and solvent (water) synergistically stabilize *O adsorbates by up to $1.5 \mathrm{eV}$.

- Free nitrogen and *O comprises the ORR environment on basal plane $\mathrm{N}$-doped graphene at $6.25 \% \mathrm{~N}$.

- Strong solvation of * $\mathrm{O}$ is observed on other materials where the ORR occurs on a 2nd row element. 

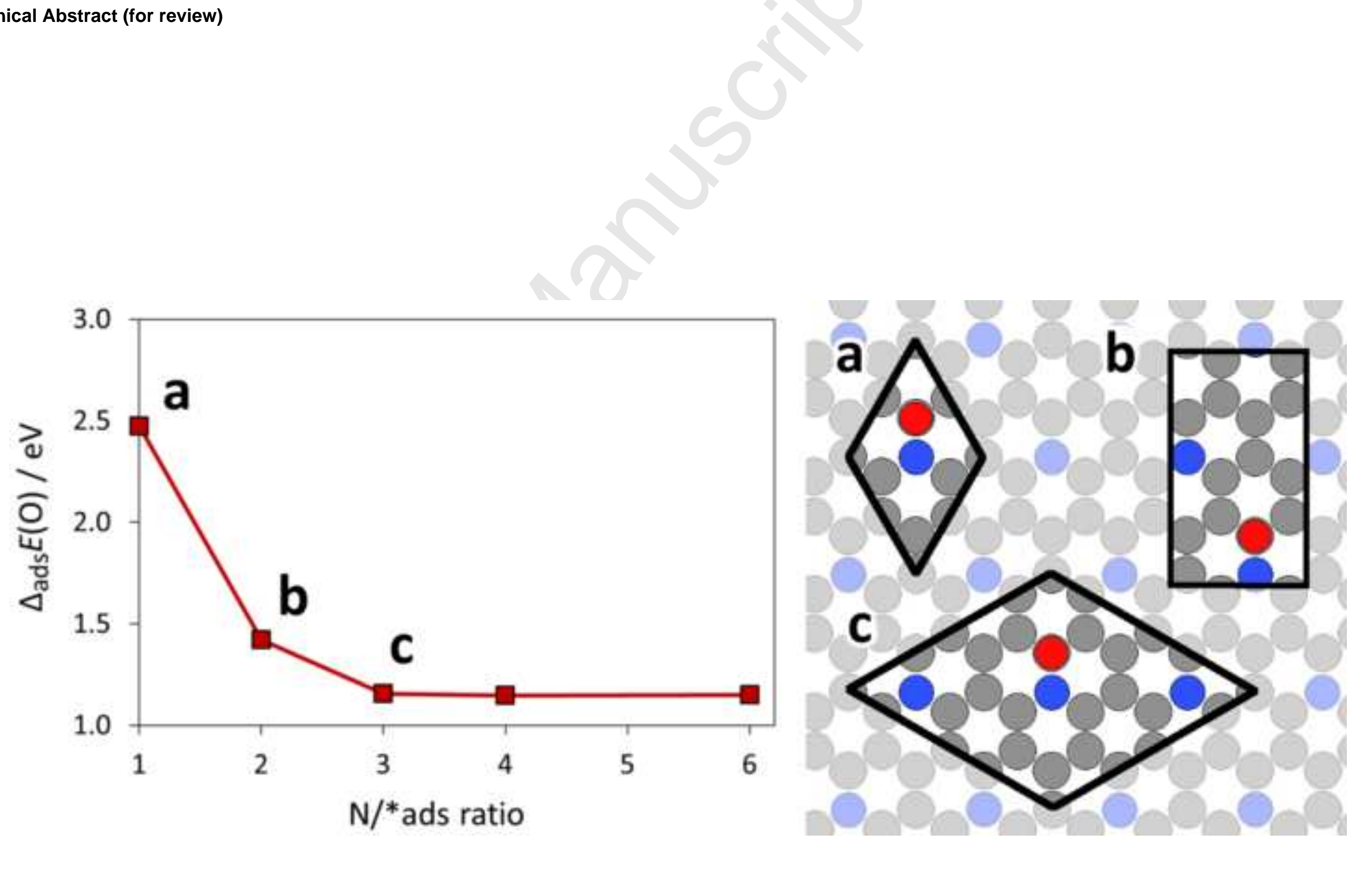

(a)

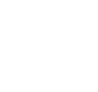

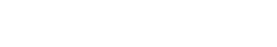

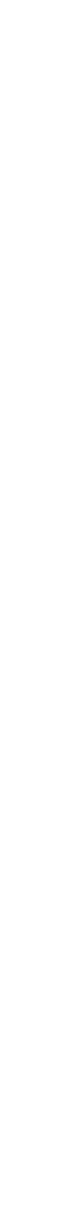

